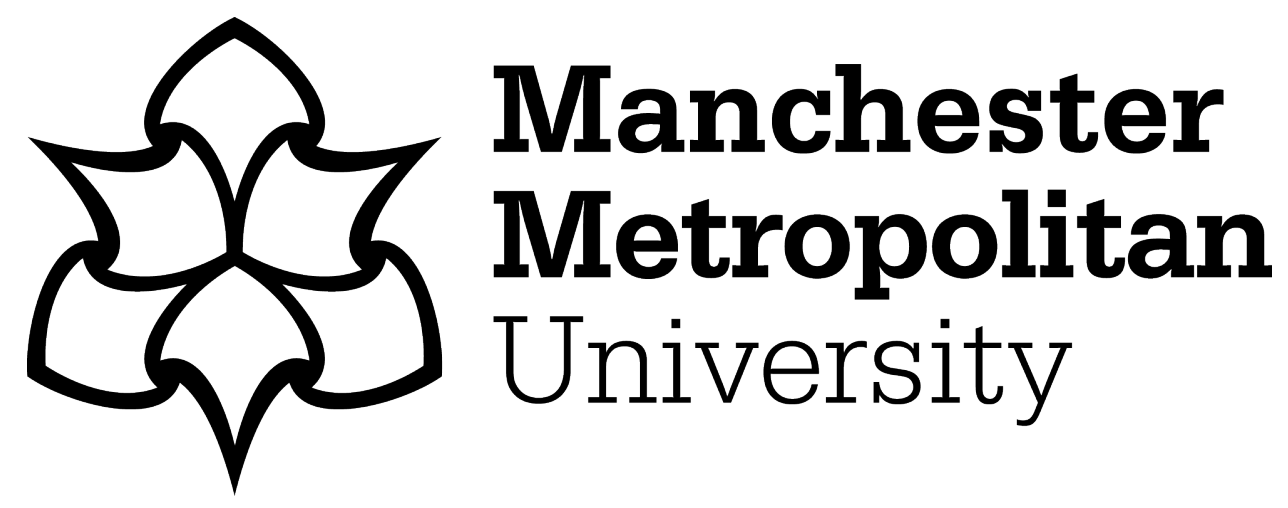

Klesse, C (2018) Dancing on the Waves or being Washed Away? Representations of Bisexualities in Liquid Modernity. Sexualities, 21 (8). pp. 13601367. ISSN 1363-4607

Downloaded from: https://e-space.mmu.ac.uk/620758/

Publisher: SAGE Publications

DOI: https://doi.org/10.1177/1363460718781540

Please cite the published version 


\section{Dancing on the Waves or being Washed Away? Representations of Bisexualities in Liquid Modernity}

\section{Christian Klesse}

'Bisexuality has come a long way in recent years. A few years ago in an article on this topic the only thing I would have felt able to say about bisexuality would have been to defend the viability of saying anything about it at all' (1999a: 309). With these words Merl Storr opens her article 'Postmodern Bisexuality', published 19 years ago in Sexualities. In this essay she sought to explain early signs of (largely tokenistic) references to bisexuality within some currents of gender, lesbian and gay, and queer studies. This had been facilitated by the consolidation of bisexual identity narratives in social movement environments and the seeds of bisexual community formation. Research and writing on bisexuality has expanded massively since then. A large number of edited collections and readers on bisexuality are now available, next to a growing body of political writing and personal testimonies (e.g. Harrad, 2016; Hutchins and Kaahumanu, 1990; Ochs and Rowley, 2009; Rodríguez Rust, 2000a; Storr, 1999b; Tucker, 1996 ). The publication of a specialist journal, the Journal of Bisexuality, has entered its $18^{\text {th }}$ year. Many of its themed special issues have also been published as books and have thus become available outside the narrow circles of an exclusively academic readership (e.g. Alexander and Yescavage, 2004; Alexander and D’Onofrio, 2012; Anderlini-D’Onofrio, 2003; Anderlini-D’Onofrio, 2004; Fox, 2004; Galupo, 2009). Some universities offer specialist units on Bisexuality Studies or at least sections of gender or sexuality-related units on bisexual phenomena. Bisexual Research Conferences (BiReCons) have been organized in the UK in conjunction with the UK Bisexual Conventions 
(BiCons) in 2008 and 2010 and the first Euro-BiReCon in conjunction with the European Bisexual Convention in 2016.

Yet bisexuality has remained marginalized in sexuality studies and within queer studies its reception has been contested and uneven (Alexander and Anderlini-D'Onofrio, 2014). There are also few signs of active engagement with the topic in the social sciences at large. A content analysis of scholarly sexuality publications within the social sciences $1970-2015$ by Monro et al. (2017) demonstrates the invisibility or exclusion of bisexuality from many key publications and its under-representation and marginalization. The authors account for the precarious position of bisexuality within the social sciences by pointing to the implications of biphobia and effects of hegemonic developments in the field of identity politics and difficulties in terms of categorization and terminology.

Bisexuality has been notoriously difficult to define. Throughout the history of the concept since its inception in the $19^{\text {th }}$ century, bisexuality has straddled contradictory positions, ranging from the universal (as in 'we are all bisexual, really') to the particular (as a minority a self-identified fringe group or a diffuse population of undecidables or 'pseudohomosexuals') to the impossible (as in 'bisexuality does not exist at all') (Angelides, 2000; Hemmings, 2002). Bisexuality has assumed a precarious position in Western discourses on sexuality, continuously evoked as a core element of sexual knowledge and/or theory yet at the same time disavowed as a feature of a mature personality. Kenji Yoshino (2000) has spoken of an 'epistemic contract of bisexual erasure' to account for the relative invisibility of bisexualities. Many bisexual activists speak of 'biphobia' or 'monosexism', i.e. the negation of or hostility towards bisexuality and bisexual-identified individuals or discrimination against those who do not limit their partner choice to one gender only (Eisner, 2012). 
Of course, there have also been periods in which bisexuality has been highly fashionable either in the world of popular culture, as for example in the wave of 1970 s bisexual chic spanning from US literary and musical counter cultures to the glossy pages of Newsweek magazine (Newsweek, 1974/2000; Rodríguez Rust, 2000b) or the short-lived blossoming in the 1990s of bisexuality as an icon of postmodern cool (Garber, 1995; Storr, 1999a). In the 1990s, some bisexual theorists toyed with the equation of bisexuality with the postmodern condition (see Hall, 1996), whereas others have been more wary of such a gesture (Dollimore, 1996). Storr (1999a) notes resonances between bisexual self and experience stories and what Ken Plummer (1995) has described as salient themes in postmodern story telling on the sexual, i.e. fragmentation, non-linearity, poly-vocality and indeterminacy. By evoking multiple possibilities and choices such stories undo sharp boundaries and coherent identities. However, the great hope that many bisexual activists and theorists had in the emergence of (postmodern) queer theory (see Off Pink Collective, 1996) quickly dissipated and gave rise to disappointment in the face of the continuous erasure of bisexualities from queer discourses (James, 1996; Young, 1997).

In spite of the dominant tendency of queer theories to avoid explicit engagement with bisexuality or to dismiss it out of hand because of its alleged investment in binary thinking, there is work that explores bisexualities from queer perspectives (Alexander and AnderliniD'Onofrio, 2014; Hemmings, 2002; Klesse, 2007). Bisexual theorists have responded to and engaged with queer thought in various ways resulting in the creation of distinct queer bisexual perspectives and a range of related but alternative epistemologies, aimed at utilizing queer's deconstructive potential (du Plessis 1996, Hemmings 2002, see Monro 2015: 43-37). 
At the same time, bisexual activism has grown, resulting in the creation of networks, permanent and temporary community spaces and the outpouring of activist writing (Eisner, 2012; Harrad, 2016; Hutchins and Kaahumanu, 1990; Off Pink Collective, 1988, 1996; Tucker, 1996; Weise, 1992). The documentation of bisexual politics has been largely confined to Anglo-Saxon countries (Burleson, 2005; George, 1993), but bisexual movements have blossomed in different world regions, including South Asia and Latin America (Monro, 2015). Some currents of bisexual identity politics have set out to campaign for the legitimacy and visibility of bisexual identity categories as a 'third mode of sexual orientation'. This is a tendency that is certainly at odds with the queer-inspired epistemological strategies described above (see Rodríguez Rust, 2000c). The efforts at articulating a bisexual rights agenda has left noticeable traces in international human rights discourses, although there is evidence of the neglect of the concern of bisexual (but also of trans*) people's predicaments in the everyday workings of the law (Waites, 2009).

While some bi activists explore bisexuality as a starting point for destabilizing and transgressing dualistic and hetero-patriarchal gender relations, heteronormativity and/or mononormativity (i.e. the naturalization of monogamy), others aim to establish bisexuality as a 'third category' of sexual orientation in a call for recognition.

Bisexualities thus relate to a complex landscape of gender and sexual politics manifested in multiple and contradictory representations and deployed for different ends in different political strategies. For many bi activists and theorists, bisexuality works as a promising sign of transgression or liberation. For orthodox queer binaryphobes it signifies insignificance, inconsequence, backwardness or delusion. For those who keep on dreaming the dream of early gay liberationists, it forbears ways of being that will be common once the powers of 
sexism, heteronormativity and gender terror have been broken. Others again read bisexualities as an epitome of the inevitable consequence of the individualizing tendencies within society that do away with traditional moulds for intimacy, coherent life courses and collective identities.

Bisexualities have long been associated with flux, instability and optionality. Those who equated bisexuality with postmodernity during the late 1990 s and afterwards have advanced this argument, usually without paying a great deal of attention to the material and economic forces that created this postmodern cultural milieu for bisexuality to tap into (Storr, 1999a). As Kath Albury (2015: 651) points out these discourses have a gender dimension and in particular 'female sexuality (...) is increasingly framed in both popular debate and sexuality research as uniquely characterized by fluidity' (cf, Diamond, 2008). In the current moment, we witness a resurgence of these representations fuelled by polls and surveys that indicate high percentages of people who report non-heterosexual identities and practices, in particular among younger people. A UK study by YouGov UK (2015) was published with the heading ' 1 in 2 young people say they are not $100 \%$ heterosexual', suggesting that $49 \%$ of $18-24$ year olds in the study used non-heterosexual identity labels, with $43 \%$ placing themselves within a non-binary spectrum. The news item was taken up by a large number of British newspapers including the Telegraph (Horton, 2015), The Daily Mail (2015), the Independent (Trayner, 2015) and the Guardian (Tandoh, 2016). It should be noted that not all young people in these studies identify precisely with the label 'bisexual', rather they express their openness to involvement with people of different genders often by opting for other labels such as omnisexual, ambisexual or 
pansexual, or refusing labels altogether. Many of these labels, such as pansexuality, are quite new and may appeal because of their novelty to younger generations.

"Pansexual" is like "queer" in that it resists definition but is defined by its elasticity. It suggests that there are more than three categories of sexuality and detaches physical sex from sexual acts' (Myers, 2009: 413). As an identity pansexuality has emerged within the context of a wholly new linguistic repertoire of referring to non-binary gender and sexual experiences. Little research has been conducted on pansexual or other non-binary populations so far. Existing studies emphasize a strong mooring of the term within the intimate and erotic cultures of young people (Callis, 2014, 2016; Graves et al., 2017). From this angle, the emergence of non-binary sexualities like pansexuality may primarily reflect a generational shift.

However, not all pansexual people approve of being subsumed under the 'bisexual umbrella'. Ayisigi Hale Gonel's (2013) research suggests that many pansexual-identified people use the label as an anti-identity to resist what they read as homonormative tendencies within mainstream LGBTQ politics and culture. Pansexuality is often used in the context of multiple identifications and is perceived by some to be an 'up-date' on bisexuality that does away with the latter's reproduction of linguistic models of gender binaries. Similarly, April Callis (2016) suggests that many pansexual-identified study participants may have consciously moved away from bisexual identifications to acknowledge transgender positions and/or gender fluidity. For many, pansexuality functions as a symbol of a 'postbisexual revolution'.

Gonel's (2013) and Callis' (2016) research reveals that 'pansexuality' appeals to people for different reasons. Some participants report that 'pansexuality' is preferable because of the 
multiple stereotypes attached to bisexuality such as promiscuity and hypersexuality. It is perceived by some as a 'safer' identity label that allows for sidestepping the experience of stigmatization within biphobic environments. Others feel the need to return to bisexuality because it is a term that is at least understood by people who have not been socialized in trans* and queer cultures or have studied on a gender studies programme. It is possible to argue therefore that bisexual and other non-binary identities are articulated in a complex landscape that is shaped by multiple forms of power and privilege, including homonormativity, biphobia and transphobia. This leads to different - at times contradictory - and often contested and/or adversarial identity claims. The frequently politicized nature of bisexual and alternative non-binary identifications that is bound up with resistance against homophobia, biphobia and transphobia (see Eisner, 2012; Monro, 2015) is dangerously under-estimated in the claims by some researchers that the alleged decline of cultural homophobia (or biphobia) leads to an unprecedented 'normalization' of bisexualities, namely among younger generations (McCormack et al., 2014, see also McCormack, 2012).

We can see that contemporary discourses on bisexualities are diverse and contradictory. $\mathrm{Bi}$ activists continue to point towards bi erasure and discrimination, which has detrimental effects on bisexual people's well-being, political participation and socio-economic positioning. Social scientists document the growth of bisexual and non-binary identifications, which is taken by some to be a sign of diversification and normalization. Media discourses report on bisexual identities among young people as if it was the ultimate sign of accelerated change and the liquidification of modernity (Bauman, 2013). Certain queer, trans* or pansexual critiques, on the other hand, portray bisexuality as a relic of the old and the reproduction of modernist dualistic gender binaries. I think we should not be 
too surprised in the face of these confused developments. The meanings of bisexuality have never been confined to a singular discourse. Bisexuals have always been the screen for multiple and contradictory - and mostly hostile - projections. Bisexual ways of lives and bisexual politics have been diverse and there has never been a singular, unified and coherent constituency of bisexual politics. In my view, this insight calls for a much more thorough scrutiny of the political and material forces that shape the landscape of contemporary gender and sexual politics around bisexualities and non-binary genders and sexualities. It also calls for a reflexive politics of alliance building in the spirit of transversal politics of 'shifting and rooting' (Yuval-Davis, 1999) that is attentive to differences both in identification and social location - within and beyond the non-binary spectrums of gender and sexual identifications.

\section{References}

Albury K (2015) Identity plus? Bi-curiosity, sexual adventurism and the boundaries of 'straight' sexual practices and identities. Sexualities 18(5-6): 649-664.

Alexander, J and Yescavage $\mathrm{K}$ (2004) Bisexuality and Transgenderism: InterSEXions of the Others. New York: Harrington Park.

Anderlini-D’Onofrio S (ed) (2004) Special Issue: Plural Loves: Designs for Bi and Poly Living. Journal of Bisexuality 4(3-4).

Anderlini-D'Onofrio S (ed) (2003) Women and Bisexuality. New York: Harrington Park.

Anderlini-D'Onofrio S and Alexander J (eds) (2014) Bisexuality and Queer Theory: Intersections, Connections and Challenges. London: Routledge.

Angelides S (2000) A History of Bisexuality. Chicago: The University of Chicago Press.

Bauman, Z (2013) Liquid Modernity. Oxford: Wiley. ProQuest Ebook Central.

Burleson WE (2005) Bi America: Myths, Truths, and Struggles of an Invisible Community, New York: Harrington Park Press.

Callis AS (2014) Bisexual, pansexual, queer: non-binary identities and the sexual borderlands. Sexualities 17(1-2): 63-80. 
Callis AS (2016) Beyond bi. Sexual fluidity, identity, and the post-bisexual revolution. In: Fischer, NL and Seidman, S (eds) Introducing the New Sexuality Studies, pp. 213-224.

Diamond L (2008) Sexual Fluidity: Understanding Women's Love and Desire. Cambridge, MA and London: Harvard University Press.

Dollimore J (1996) Bisexuality, heterosexuality and wishful theory. Textual Practice 10(3): 523-39.

du Plessis M (1996) Blatantly bisexual; or, unthinking queer theory. In: Hall DE and Pramaggiore M (eds) RePresenting Bisexualities. Subjects and Cultures of Fluid Desire. London and New York: New York University Press, pp. 19-54.

Eisner S (2012) Bi Notes for a Bisexual Revolution, Berkley, CA: Seal Press.

Fox C (2004) Current Research on Bisexuality. New York: Harrington Park.

Galupo MP (ed) (2009) Bisexuality and Same-Sex Marriage. London, UK: Routledge.

Garber M (1995) Vice Versa. Bisexuality and the Eroticism of Everyday Life. London: Hamish Hamilton.

George S (1993) Women and Bisexuality. London: Scarlet Press.

Gonel AH (2013) Pansexual identification in online communities: employing a collaborative queer method to study pansexuality. Graduate Journal of Social Science, February 2013, 10(1): 36-59.

Greaves LM, Barlow FK, Lee CHJ et al. (2017)_The diversity and prevalence of sexual orientation self-labels in a New Zealand national sample. Archives of Sexual Behaviour 46(5): 1325-1336.

Hall DE (1996) BI-ntroduction II: epistemologies of the fence. In: Hall DE and Pramaggiore M (eds) RePresenting Bisexualities. Subjects and Cultures of Fluid Desire. New York: New York University Press, pp. 8-16.

Harrad K (2016) Purple Prose: Bisexuality in Britain. Portland, OR: Thorntree Press.

Hemmings C (2002) Bisexual Spaces. Geography of Sexuality and Gender. London: Routledge.

Horton $\mathrm{H}$ (2015) Nearly half of young people don't think they are exclusively heterosexual. The Telegraph, 17 August 2015. Available at:

http://www.telegraph.co.uk/news/uknews/11807740/half-young-people-heterosexual-lgbthomosexual-yougov.html (accessed 7 October 2017).

Hutchins L and Kaahumanu L (ed.) (1990) By any other Name. San Francisco, CA: Alyson.

James C (1996) Denying complexity: the dismissal and appropriation of bisexuality in queer, lesbian, and gay theory. In: Beemyn B and Eliason M (eds) Queer Studies. A Lesbian, Gay, Bisexual, and Transgender Anthology. New York: New York University Press, pp. 217-239.

Klesse C (2007) The Spectre of Promiscuity, Gay Male and Bisexual Non-monogamies and Polyamories. Aldershot: Ashgate.

McCormack M (2012) The Declining Significance of Homophobia. How teenage boys are redefining masculinity and heterosexuality. Oxford: Oxford University Press. 
McCormack M, Andersen E and Adams A (2014) Cohort effect on the coming out experiences of bisexual men. The Sociological Review 48(6): 1207-1223.

Monro S (2015) Bisexuality: Identities, Politics, and Theories, London: Palgrave Macmillan.

Monro S, Hines S and Osborne A (2017) Is bisexuality invisible? A review of sexualities scholarship 1970-2015. The Sociological Review. Available at:

http://journals.sagepub.com/doi/pdf/10.1177/0038026117695488 (accessed on 7 October 2017).

Myers AM (2009) Allowing for cultural discussion of queerness and pansexuality:

sex/gender/sexual belief systems, the religion clauses, and the ideal of pluralism, Stetson Law Review 38(2): 409-457.

Newsweek (1974/2000) Bisexual chic: anyone goes. In: Rodríguez Rust PC (ed) Bisexuality in the United States. A Social Science Reader. New York: Columbia University Press, pp. 554555.

Ochs R and Rowley SE (eds) (2009) Getting Bi. Voices of bisexuals around the world (2 ${ }^{\text {nd }}$ edition). Boston, MA: Bisexual Resource Centre.

Off Pink Collective (ed) (1996) Bisexual Horizons. Politics, Histories, Lives. London: Lawrence \& Wishart.

Off Pink Collective (eds) (1988) Bisexual Lives. London: Off Pink Publishing.

Plummer K (1995) Telling Sexual Stories. Power, Change and Social Worlds, London:

Routledge.

Rodríguez Rust PC (2000) Popular images and the growth of bisexual community and visibility. In: Rodríguez Rust PC (ed) Bisexuality in the United States. A Social Science Reader. New York: Columbia University Press, pp. 537-553.

Rodríguez Rust PC (2000c) Alternatives to binary sexuality: modelling bisexuality'. In:

Rodriguez Rust PC (ed) Bisexuality in the United States. A Social Science Reader. New York:

Columbia University Press, pp. 33-54.

Rodríguez Rust PC (ed) (2000a) Bisexuality in the United States. A Social Science Reader. New York: Columbia University Press.

Storr M (1999a) Postmodern bisexuality. Sexualities 2(3): 309-325.

Storr M (ed) (1999b) Bisexuality: A Critical Reader. London: Routledge.

Tandoh R (2016) Being bisexual is on the up - so how come people think I just can't decide? The Guardian, 3 December 2016, Available at:

https://www.theguardian.com/society/2016/dec/03/being-bisexual-ruby-tandoh-commentst-vincent-cara-delevingne (accessed 29 September 2017).

Trayner D (2015) Half of all young people in Britain are at least a little bit gay, survey finds, The Independent, 16 August 2015. Available at:

http://www.independent.co.uk/news/uk/home-news/yougov-poll-homosexuality-halfyoung-people-10458032.html (accessed on 7 October 2017).

Tucker N and Highleyman L (with Kaplan R.) (eds.) (1996) Bisexual Politics. Theories, Queries \& Visions. New York: Harrington Park Press. 
Waites M (2009) Critique of 'sexual orientation' and 'gender identity' in human rights discourse: global queer politics beyond the Yogyakarta Principles. Contemporary Politics 15(1): 137-156.

Weise R (ed) (1992) Closer to Home: Bisexuality and Feminism. Seattle: Seal Press

Williams A (2015) Half of young Brits say they are 'not exclusively heterosexual' with a quarter of all UK adults saying they are gay or bisexual, 17 August 2015. Mail Online. Available at: http://www.dailymail.co.uk/news/article-3201071/Half-young-Brits-say-notexclusively-heterosexual-quarter-UK-adults-saying-gay-bisexual.html (accessed on 7 October 2017).

Yoshino K (2000) The epistemic contract of bisexual erasure. Stanford Law Review 52(2): 353-461.

YouGov UK (2015) 1 in 2 young people say they are not 100\% heterosexual. Available at: https://yougov.co.uk/news/2015/08/16/half-young-not-heterosexual/_(accessed 29 September 2017).

Young S. (1997) Dichotomies and displacement: bisexuality in queer theory and politics. In: Phelan S (ed) Playing with Fire. London: Routledge, pp. 51-76.

Yuval-Davis N. (1999) What is transversal politics? Soundings 12: 94-98. 